\title{
Assessment of the fungal isolates interactions by laboratory culture technique with brown lentil seeds germination using vermicompost suspension
}

\author{
Sally A. Ali ${ }^{1}$, Mannar Kassem², Yasmin Omar ${ }^{2}$ and Abdel-Aziz \\ Abdel-Naby ${ }^{2}$
}

1-Department of Botany and Microbiology, Faculty of Science, Helwan Univ., Cairo, Egypt

2- Department of Biotechnology, Faculty of Science, Helwan Univ., Cairo, Egypt.

*Corresponding author email: Sally_ali@ science.helwan.edu.eg

Received: January 5, 2020; Accepted: January 30, 2021; Available online: Feb. 2, 2021

ABSTRACT
This study focuses on the interactions among vermicompost fungi and vermicompost's ability to enhance seed germination by cultivatingbrown lentil seeds through using filter paper and pertri-dishes technique. Vermicompost prepared by using waste materials and earthworms was used for fungal isolation and lentil seed germination in the suspended form. The interaction among vermicompost fungi was observed during direct isolations using the serial dilution method and then using pure culture dual plate's plans. At the same time, brown lentil seed germination was occurred using vermicompost suspension and measuring seed germination percentage method. The results revealed that most isolated microorganisms were fungi. Interaction among vermicompost fungi varied from neutral to negative interaction. The brown lentil seedsachieved a high germination percentage $(80 \%)$ using vermicompost suspension compared to a positive and negative control. The overall results confirmed that the vermicomposting fungi play an essential role as biological control and growth-promoting factor.

Keywords: Fungal isolates, brown lentil, seed germination, vermicompost suspension.

\section{INTRODUCTION}

The interactions among microorganisms occurbetween the same species, with different species, or even betweenentirely other genera and families. The interactive patterns within these webs are positive, negative, or neutral, where there is no effect on the interacting species (Faust and Raves, 2012).The microbial communities influence life extended in various disciplines; for example, humanassociated micro-biotaimpacts health, environmental microbes determine ecosystem sustainability, and microbedriven industrial processes expand (Zaccaria et al., 2017).The production of synthetic fertilizer known as NPK (Nitrogen, Phosphorus, and Potassium) relies on mining phosphate rock's increasingly costly process. Global phosphate reserves are known to reach complete exhaustion within the next 50100 years, hitting peak extraction by 2030 (Cordell et al., 2009). Since 2006 the price of phosphate has doubled, and between 2007-2008 the cost of synthetic fertilizer increased 800\% (Tomlinson, 2010).

Vermicompost is a bio-oxidative process in which the earthworms interact with microorganisms and other fauna within the decomposer community, accelerating the stabilization of organic matter and significantly modify its physical and biochemical properties (Dominguez, 2004), which act as an essential biological process in the management and recycling of organic wastes, it provides a way to treat organic wastes more quickly (Lazcano et al., 2008). Although, microorganisms primarily accomplish the biochemical decomposition of organic matter, yet, 
Sally A. Ali et al.

earthworms are crucial drivers of the process. They are involved in microbial populations' stimulation through ingestion and fragmentation of fresh organic matter, which results in a greater surface area available for microbial colonization, thereby drastically altering biological activity (Dominguez et al.,2010).

Earthworms modify microbial biomass and activitythrough stimulation, digestion, and dispersion in casts (Brown and Double, 2004; Aira et al., 2009; Monroy et al., 2009) and closely interact with other biological components of the vermicomposting system, affecting the structure of microflora and microfauna communities (Dominguez et al., 2003; Lores et al., 2006; Aira et al.,2007; Monroy et al., 2009). Vermicompost provides a stable mineral balance, improves the nutrient availability for plant growth,and could act as a complex bio-fertilizer rejuvenating the soil. The mutual uses of vermicompost with soil will build up high bacterial populations that improve plant growth and fall of pathogenic organisms else.

\section{Lentilseeds} add essential vitamins, minerals, and fiber to the diet, also provide protein, and are an excellent replacement for meat in meals; they decrease the risk of heart disease by reducing blood pressure naturally; also contains the carotenoids, lutein, zeaxanthin and

polyunsaturated fatty acids (Zhang et al., 2014). The interaction between vermicomposting and isolated microorganisms such as fungi was evaluated and also using the vermicompost suspension for brown lentil seed germination was investigated.

\section{MATERIALS AND METHODS 1. Vermicompost preparation}

Vermicompost was prepared by mixing60 kgrabbits wastes (which have high protein content and less toxic effect), 40 Kgrice straw (as sheep plant source), andonekg worms (A mixture of earthworms, red wigglers, and tiger worms) for 75 days at $\mathrm{pH} 7,15-35^{\circ} \mathrm{Cand}$ moderate moisturewas kept by continuously adding water every week (Figs. 1 \& 2).Worms were obtained from Al monakh Lab, at the National Center for

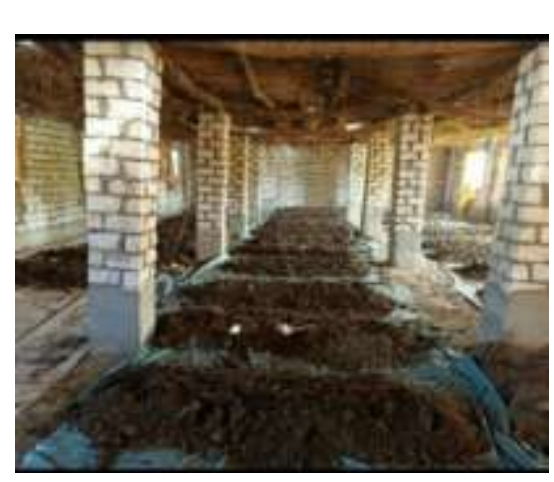

Land and Water Research, Cairo, Egypt.

Fig.(1).Vermicompost preparation method at farm.

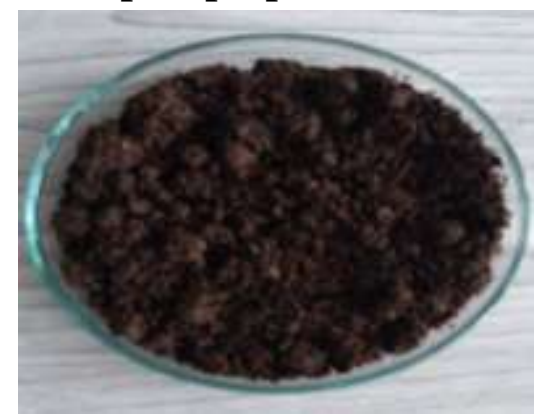

Fig.(2).Vermicompost. 


\section{Assessment of the fungal isolates interactions by laboratory culture technique with brown lentil seeds germination using vermicompost suspension}

\section{Physicochemical characteristics of vermicompost}

The produced vermicompost was analyzed to detect the total elements, hormones, and other organic contents through the Agricultural research center, Soil Water, Environmental Research Institute, Giza, and Egypt.

3. Microbial isolation from vermicompost

a. Isolation technique

Microbial isolation was carried out using serial dilution methods (Benso, 2002), firstly after storage vermicompost at $4{ }^{\circ} \mathrm{C}$ for 30 minutes. After storage at room temperature for 30 minutes, $10 \mathrm{~g}$ of vermicompostsamplewas addedtoa $250 \mathrm{ml}$ Erlenmeyer flask, each contains $100 \mathrm{ml}$ of sterilized distilled water. Flasks were then shaken at a constant speed (150 RPM) for 15 minutes at room temperature. The flasks were left until complete sedimentation of compost. Serial decimal dilutions were prepared from an original concentrated to reach dilution $1 / 10^{-7}$. Then one $\mathrm{ml}$ aliquot from required dilutions was transferred to Petri-plates; three replicates were prepared for each dilution. The sterilized and cooled media were transferred to respective pre-labeled plates like potato dextrose agar media. After plating, plates were incubated at $27^{\circ} \mathrm{C}$ for 4 to 7 days,the pure culture was obtained by repeated streak plate method.

\section{b. Identification of fungal isolates}

Identification of fungal isolates was carried out at Mycology laboratory (Botany and Microbiology Department, Faculty of Science, Helwan University and it was based on morphological characteristics of each culture using the following references (Gilman, 1957; Johnand Pit, 1979; Thom an Raper, 1945; Toussoun and Nilson, 1983).
4. The interaction studies

I. Direct isolation from vermicompost sample (mixed culture)

1. Make a serial dilution of vermicompost sample (Benson,2002).

2. Inoculate $0.1 \mathrm{ml}$ of each dilution into sterilized perti-dishes.

3. Pour the molten medium $\left(45^{\circ} \mathrm{C}\right)$ into the petri-dishes (use potato dextrose agar media).

4. Shake well and incubate at $28^{\circ} \mathrm{C}$ for 3 5 days.

5. Examination of the plates. (Especially for $10^{-3}$ and $10^{-4}$ ) and determine the interaction.

II. Determine the interaction between pure cultures isolated from the vermicompostsample

1. Pour the medium (use potato dextrose agar media) in sterilized petri-dishes and after solidification, inoculate thetested fungi near each other.

2.Incubate at $28^{\circ} \mathrm{C}$ for 3-5 days.

4. Observe the manner of growth by thedual culture method (Skidmore and Dickenson, 1976).

\section{Lentil seed germination using} vermicompost suspension

The present study was carried out using petri-dishes $(9 \mathrm{~cm}$ in diameter), which contained filter paper (Double ring $9 \mathrm{~cm}$ ) and Brown lentil (50 seeds of brown lentil), then adding $10 \mathrm{ml}$ of vermicompost suspension (10 g vermicompost $+100 \mathrm{ml}$ sterilized distilled water). For -ve control sets, $10 \mathrm{ml}$ sterilizedistilled water was used, while for +ve control, $10 \mathrm{ml}$ autoclaved vermicompost suspension was used. All treated sets were incubate at room temperature. Thegermination percentage, and length of the plumule and radicle were recorded over four days for all sets. 
Sally A. Ali et al.

RESULTS AND DISCUSSION

1.Physicochemical characteristics of vermicompost

Analysis of vermicompost (Table

1) indicated that its physicochemical characteristics were greatly similar to the findings of Pasupathi and Devendiran
(2018), who found that the $\mathrm{pH}$ ranged between 7.1-7.9, Organic Carbon 20-26\%, moisture content 22-66.7\%, nutrients $(\mathrm{N}=$ $1.16 \%),(\mathrm{P}=0.04 \%),(\mathrm{K}=0.34 \%),(\mathrm{Na}=$ $2.89 \%)$ and microbial colonies like Bacteria, Fungi, and Actinomycetes were also present in large numbers.

Table(1).The physicochemical characteristics of vermicompost.

\begin{tabular}{|c|c|c|}
\hline Item & Unit & Value \\
\hline Density & $\mathrm{Kg} / \mathrm{m} 3$ & 585 \\
\hline Moisture content & $\%$ & 62 \\
\hline $\mathrm{pH}(1: 10)$ & $\%$ & 7.9 \\
\hline Total nitrogen & $\%$ & 1.82 \\
\hline Ammonical nitrogen & PPM & 76 \\
\hline Nitrate nitrogen & PPM & 38 \\
\hline Organic matter & $\%$ & 47.14 \\
\hline Organic Carbon & $\%$ & 27.34 \\
\hline Ash & $\%$ & 52.86 \\
\hline C/N Ratio & & $15: 1$ \\
\hline Total phosphorus $\left(\mathrm{P}_{2} \mathrm{O}_{5}\right)$ & $\%$ & 1.13 \\
\hline Total Potassium $\left(\mathrm{K}_{2} \mathrm{O}\right)$ & $\%$ & 0.80 \\
\hline Weed seeds & & $\mathrm{Nd}$ \\
\hline Nematoda & Larva/200g & $\mathrm{Nd}$ \\
\hline Germination index & $\%$ & 90 \\
\hline Total potassium humate & $\%$ & 0.95 \\
\hline Humic acids & $\%$ & 0.82 \\
\hline Fulvic acids & $\%$ & 0.11 \\
\hline Total coliform bacteria & $\mathrm{Cfu} / \mathrm{g}$ & $\mathrm{Nd}$ \\
\hline Fecal coliform bacteria & $\mathrm{Cfu} / \mathrm{g}$ & $\mathrm{Nd}$ \\
\hline Salmonella and shigella bacteria & $\mathrm{Cfu} / \mathrm{g}$ & $\mathrm{Nd}$ \\
\hline Total count of bacteria & $\mathrm{Cfu} / \mathrm{g}$ & $15 \times 10^{5}$ \\
\hline Total count of fungi & $\mathrm{Cfu} / \mathrm{g}$ & $20 \times 10^{5}$ \\
\hline Total count Actinomycetes & $\mathrm{Cfu} / \mathrm{g}$ & $4 \times 10^{5}$ \\
\hline
\end{tabular}

Previous determinations were calculated on dry weight basis except for moisture content and density. $\mathrm{Nd}=$ not detected $\quad \mathrm{CFU}=$ Colony Forming Unit.

\section{Fungal isolates}

The results in Table (3) show that seven fungal species have been isolated from vermicompost, and the highest fungal population was recorded in vermicompost which storaged at $4^{\circ} \mathrm{C}$ for 30 minutes, compare to vermicompost storaged at room temperature for 30 minutes. These fungal species were identified as Aspergillus flavus, Aspergillus niger, Aspergillus tamarii, Rhizopus stolonifer, Alternaria sp, Penicillumsp and 
Assessment of the fungal isolates interactions by laboratory culture technique with brown lentil seeds germination using vermicompost suspension

Aspergillus nidulas (Table 3).This result may be due to temperature plays an essential role in the growth of microbial colonies during composting of municipal solid waste as has been mentioned by Pathaka et al. (2012).

Table(2). Brown lentil seed germination

\begin{tabular}{|l|l|l|l|}
\hline \multirow{2}{*}{ Parameters } & \multicolumn{3}{|c|}{ Treatments } \\
\cline { 2 - 4 } & $\begin{array}{l}\text { Negative } \\
\text { control } \\
(\text { Dist.H }\end{array}$ & $\begin{array}{l}\text { Positive } \\
\text { control(Autoclaved } \\
\text { vermicompost } \\
\text { suspension) }\end{array}$ & $\begin{array}{l}\text { Vermicompost } \\
\text { suspension }\end{array}$ \\
\hline Germination (\%) & $\mathbf{5 0 \%}$ & $\mathbf{6 0 \%}$ & $\mathbf{8 0 \%}$ \\
\hline Plumule length $(\mathrm{cm})$ & $\mathbf{2}$ & $\mathbf{3}$ & $\mathbf{2}$ \\
\hline Radicle length $(\mathrm{cm})$ & $\mathbf{1 . 3}$ & $\mathbf{1 . 5}$ & \multicolumn{2}{|c|}{} \\
\hline
\end{tabular}

Table(3). Morphological identification of the fungal isolates.

\begin{tabular}{|l|l|l|}
\hline \multicolumn{2}{|l|}{ Fungal isolates number } & \multirow{2}{*}{ Identification } \\
\cline { 1 - 2 } $\begin{array}{l}\text { After storage at } \\
\mathbf{4}^{\circ} \mathbf{C}\end{array}$ & $\begin{array}{l}\text { After storage at } \\
\text { room temperature }\end{array}$ & \\
\hline 1 & 1 & Aspergillus nigerVan Tieghem \\
\hline 2 & - & Aspergillus tamari Kita \\
\hline 3 & - & Aspergillus flavus Link \\
\hline 4 & - & Aspergillus nidulans (Eidam) Wint \\
\hline 5 & 2 & Penicillum chrysogenum Thom \\
\hline 6 & - & Rhizopus stolonifer (Ehrenberg)Vuillemin \\
\hline 7 & 3 & Alternaria alternate (Fr)Keissl \\
\hline
\end{tabular}

\section{The interaction studies}

The results in Figures $(3,4 \& 5)$ show the interaction between fungi of vermicompost which varies from negative interaction to neutral one. This result agrees with that of Belen et al. (2020) and helps to understand the impact of fungi of vermicomposton the plant. Also, explainstheir ability to prevent the growth of pathogenic fungi such as Apergillus nigeras part of biological control strategies. On the other hand, Pei-Hua et al. (2018) indicated that antagonistic yeast strains inhibited $B$. cinerea and those with high potential for sustainable strawberry production.

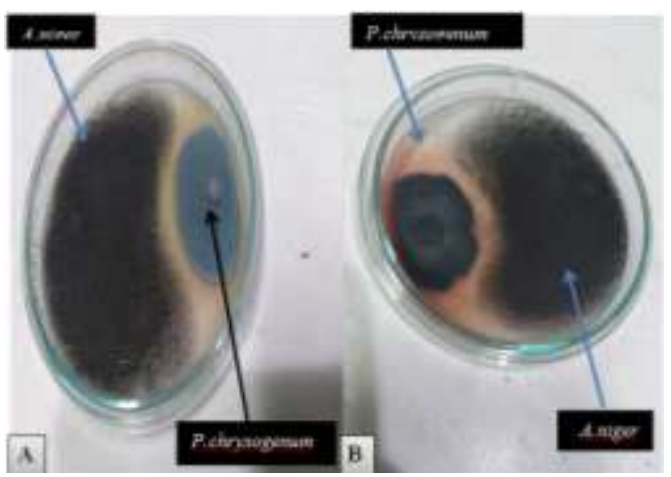

Fig.(3).Deviation of growth (negative interaction) using pure culture of Aspergillus niger and penicillum chrysogenum Thom. 
Sally A. Ali et al.
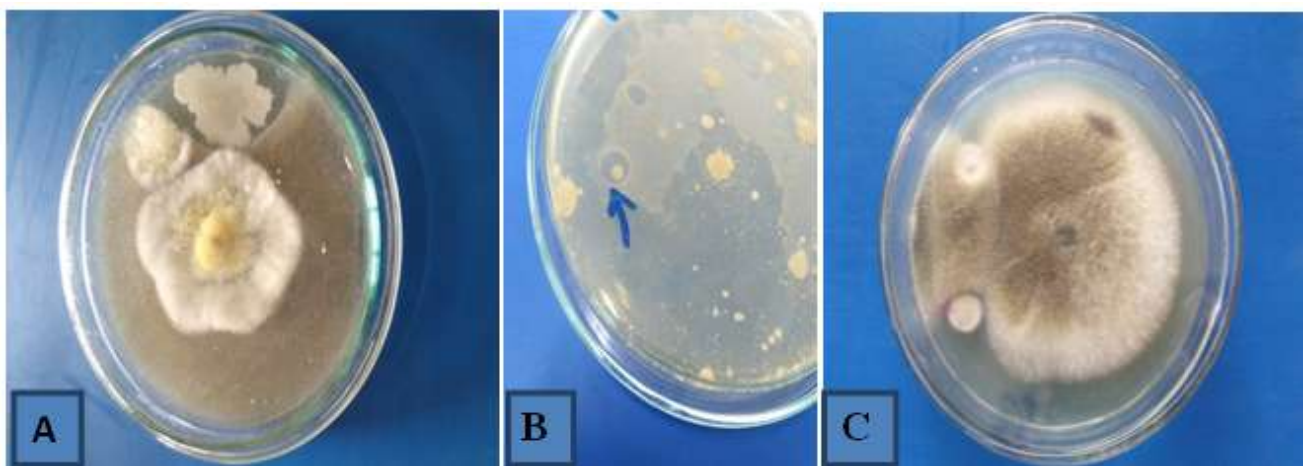

Fig. (4).A, C deviation of growth and B, clear zone using direct isolation (negative interaction).
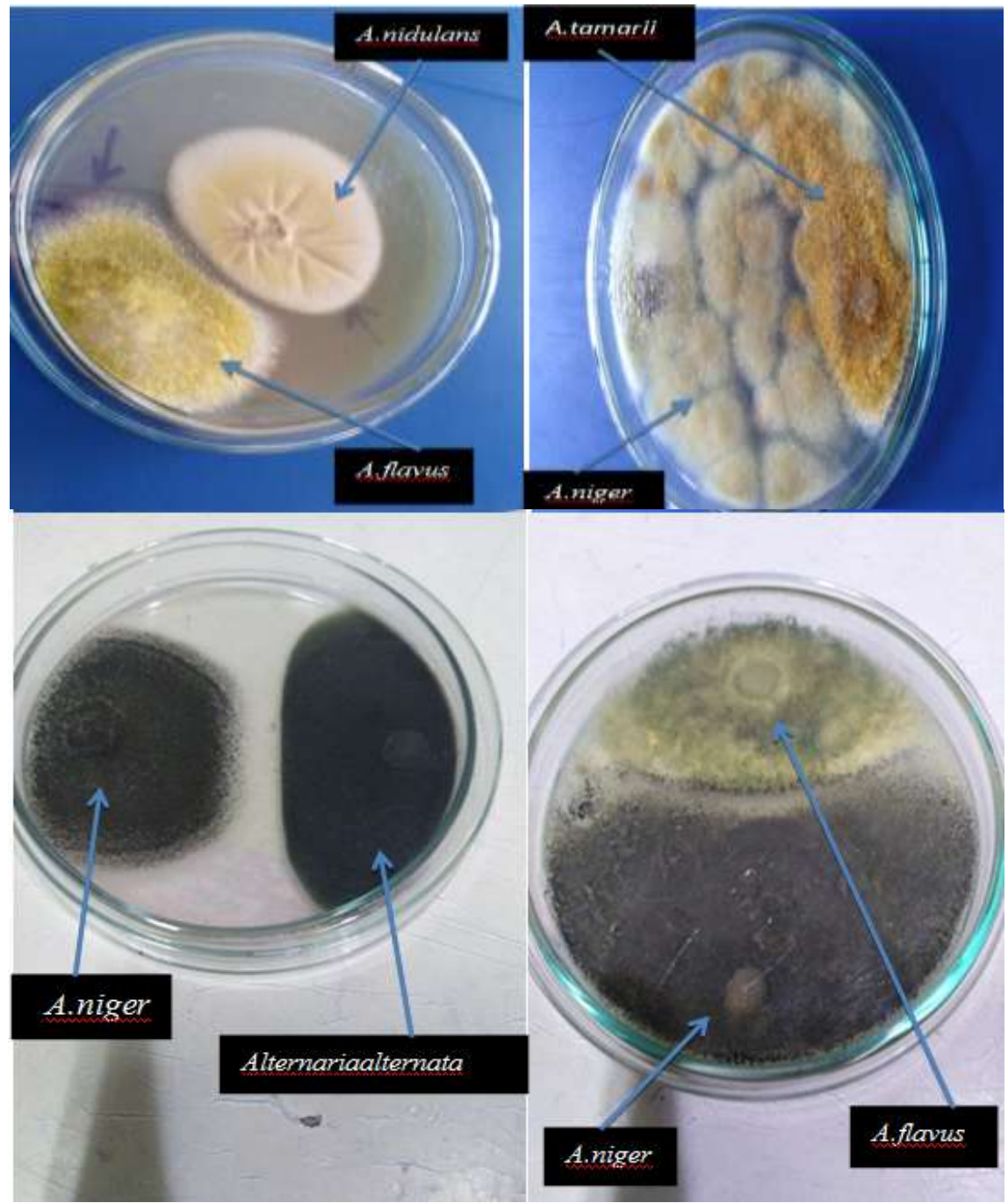

Fig.(5).Neutral interaction using pure culture of Aspergillus niger, Apergillus tamarii, Aspergillus flavus, Apergillus nidulas and Alternaria alternata.

\section{Brown lentil seed germination}

The present results indicated the ability of lentil seeds to achieve the highest germination percentage $(80 \%)$ using vermicompost suspension compared to negative and positive control one (Fig. 6 and Table 2). This in agreement with Norman et al. (2012)who observed thatgermination percentage increased when seeds were soaked in a 


\section{Assessment of the fungal isolates interactions by laboratory culture technique with brown lentil seeds germination using vermicompost suspension}

vermicompost extract from chicken manure compared with seeds soaked in water. This suggests that factors beyond physical alteration of seed coats were responsible for earlier and better germination. Spaccini et al. (2008) reported that aerated compost extracts contain low-molecular-weight bioactive microbial origin compounds. Arancon et al. (2007) demonstrated that applying a vermicompost extract to growth media enhanced seed germination and seedling growth of tomatoes and cucumbers. Lazcano et al. (2010) reported positive effects of vermicompost extracts on the germination and early development of Pinus pinaster.
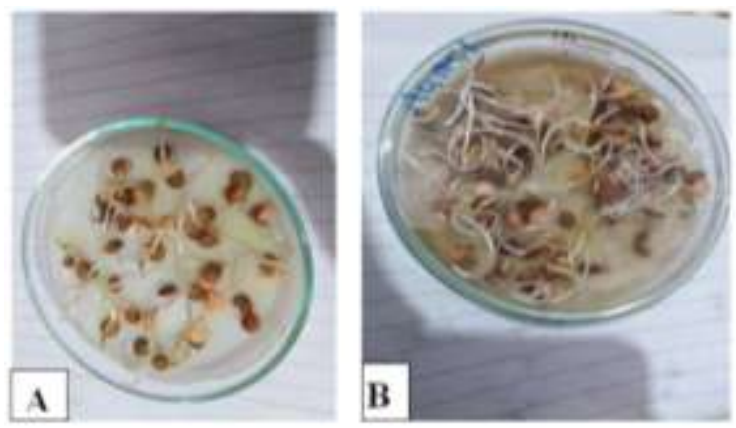

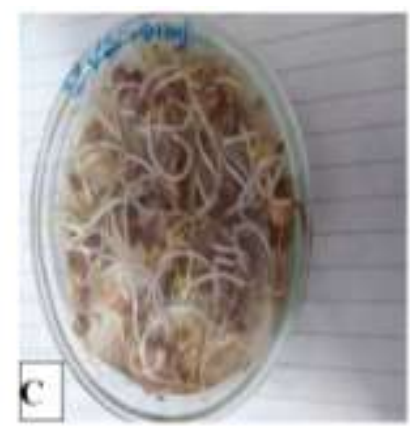

Fig.(6). Brown lentil seed germination, A (-ve control), B (+ ve control) and C (vermicompost suspension).

\section{Conclusions}

Vermicompost prepared using rabbit wastes and rice straw as a source for worm breeding was suspended for fungal isolation to germinate the lentil seeds. The results indicated the ability of vermicompost fungi to interact using different laboratory techniques through petri-dishes. Also, indicated the ability of vermicompost suspension to promote seed germination of brown lentil.

\section{Acknowledgment}

This work has beensupported by the JisrAl Khayr program for vermicompost preparation. Also, it was supported byMycology Lab, Faculty of Science, Helwan University to perform the isolation andthe interaction studies, in addition to lentil seed germination.

\section{REFERENCES}

Aira, M.; Monroy, F. and Dominguez, J. (2007). Earth worms strongly modify microbial biomass and activity triggering enzymatic activities during vermicomposting independently of the application rates of pig slurry. Sci. Total Environ., 385(1-3): 252-261.

Aira, M.;Monroy, F. and Dominguez, J. (2009). Changes inbacterial numbers and microbial activity of pig slurry during gut transit of epigeic and anecic earthworms. J. Hazard Mater., 162(2-3): 14041407.

Arancon, N.Q.; C.A. Edwards, R.D. and L. Dick (2007).Vermicompost tea production and plant growth impacts. Biocycle, 48:51-52.

Belén, C.;Thibault, N.; Stéphane, G.; Marc, P.; Diego, S. and Delphine, S. (2020). Interactions between Kazachstania humilis yeast species and lactic acid bacteria in Sourdough.

Microorganisms, 8(2):240; https://d oi.org/10.3390/microorganisms802 0240 .

Benson, H.J. (2002). Microbiological applications $8^{\text {th }}$ ed., New York. 2926. 
Sally A. Ali et al.

Brown, G.G. and Doube, B. (2004). Functional interactions between earthworms, microorganisms, organic matter and plants. Earthworm Ecology, $2^{\text {nd }}$ ed. London; Boca Raton, FL, USA: CRC Press; 213-240.

Cordell, D.; Drangert, J. and White, S. (2009). The story of phosphorus: global food security and food for thought. Global Environ. Change, 19 (2):292-305.

Domínguez, J.; Parmelee, R.W. and Edwards, C.A. (2003).Interactions between Eisenia andrei (Oligochaeta) and nematode populations during vermicomposting. Pedobiologia, 47: 53-60.

Domínguez, J. (2004). State of the art and new perspectives on vermicomposting research. In: Edwards, C.A. (Ed.), Earthworm Ecology, $2^{\text {nd }}$ ed. CRC Press, Boca Raton FL USA.; 401-424.

Domínguez, J.; Aira, M. and GómezBrandón, M. (2010). Vermicomposting: earthworms enhance the work of microbes. Microbes at Work: from Wastes to Resources. Springer-Verlag, Berlin Heildelberg, 93-114.

Faust, K. and Raes, J. (2012). Microbial interactions: from networks to models. Nat. Rev. Microbiol., 10: 538-550.

Gilman, J.C. (1957). A manual of soil fungi.The maple Press Co. New York, 208-339.

John, P. (1979). The genus Penicillium and its telemorphic states Eupenicillium and Talaromyces. Academic Press. London. New York. Toronto, Sydeny. San Francisco, 634.

Lazcano, C.; Sampedro,L.; Zas, R. and Dominguez, J. (2010). Vermicompost enhances germination of the maritime pine (Pinu sp inaster At.). New Forests,
39:387-400. DOI 10.1007/s11056009-9178-z.; 39:387-400.

Lazcano, C.; Gómez-Brandón, M. and Domínguez, J. (2008). Comparison of the effectiveness of composting and vermicomposting for the biological stabilization of cattle manure. Chemosphere, $\quad 72(7)$ : 1013- 1019.

Lores, M.; Gómez-Brandón, M.; PérezDíaz, D. and Domínguez, J. (2006). Using FAME profiles for the characterization of animal wastes and vermicomposts. Soil Biol. Biochem., 38: 2993-2996.

Monroy, F.; Aira, M. and Domínguez, J. (2009). Reduction of total coliform numbers during vermicomposting is caused by short-term direct effects of earthwormson microorganisms. It depends on the dose of application of pig slurry. Sci. Tot.Environ., 407: 5411-5416.

Norman, Q.;Arancon, A.P.; Theodore, R.; Nguyen, V.; Hue, J.K.; Potter, C.E.C. (2012).Seed germination and seedling growth of tomato and lettuce as affected by vermicompost water extracts (Teas). Hortsience, 47 (12): 17221728.

Pasupathi, S. and Devendiran, D. (2018). Studies on the screening of bacterial and fungal population from vermicompost and compost. Terrestrial and Mar. Res., 2(4): 821.

Pathaka, A.K.; Singhb, M.M.; Kumara, V.; Aryaa, S. and Trivedi, A.K.(2012). Res. Sci. Technol., 4(4):10-14.

Pei-Hua, C.; Rou-Yun, C. andJui-Yu, C. (2018).Screening and evaluation of yeast antagonists for biological control of Botrytis cinerea on strawberry fruits. Mycobiol., 46:33-46.

Skidmore, A.M. and Dickenson, C.M.(1976).Colony interaction and hyphae interference between septorianodorum and 


\section{Assessment of the fungal isolates interactions by laboratory culture technique with brown lentil seeds germination using vermicompost suspension}

phylloplanefungi.Trans. Br. Mycol. Soc., 66: 167-171.

Spaccini, R.; Baiano, G. and Giliotti, P.A. (2008). Molecular characterization of compost and its water soluble fractions. Agr. Food Chem., 56: 1017-1024.

Thom, G. and Raper, K. (1945). A manual of the Aspergilli. Williams and Wilkins Co. Baltimore, 363.

Tomlinson, I.(2010). Food figures need a pinch of salt. (http://news.bbc.co.uk/2/hi/science/ nature/8946555.stm).

Toussoun, T. and Nilson, E. (1983). Fusarium species: an illustrated manual for Identification. Pennsylvania State University Press, 193.
Zaccaria, M.; Dedrick, S. and Momeni, B. (2017). Modeling microbial communities: a call for collaboration between experimentalists and theorists. Processes, 5:53.

Zhang, B.; Deng, Z.; Tang, Y.; Chen, P.; Liu, R.; Ramdath, D.; Dan, L.; Qiang, H.; Marta, T. andRong, A. (2018). Fatty acid, carotenoid and tocopherol compositions of 20 Canadian lentil cultivars and synergistic contribution to antioxidant activities. Food Chem., 2014; $\quad$ 161: 296-304. doi:10.1016/j.foodchem.04.014.

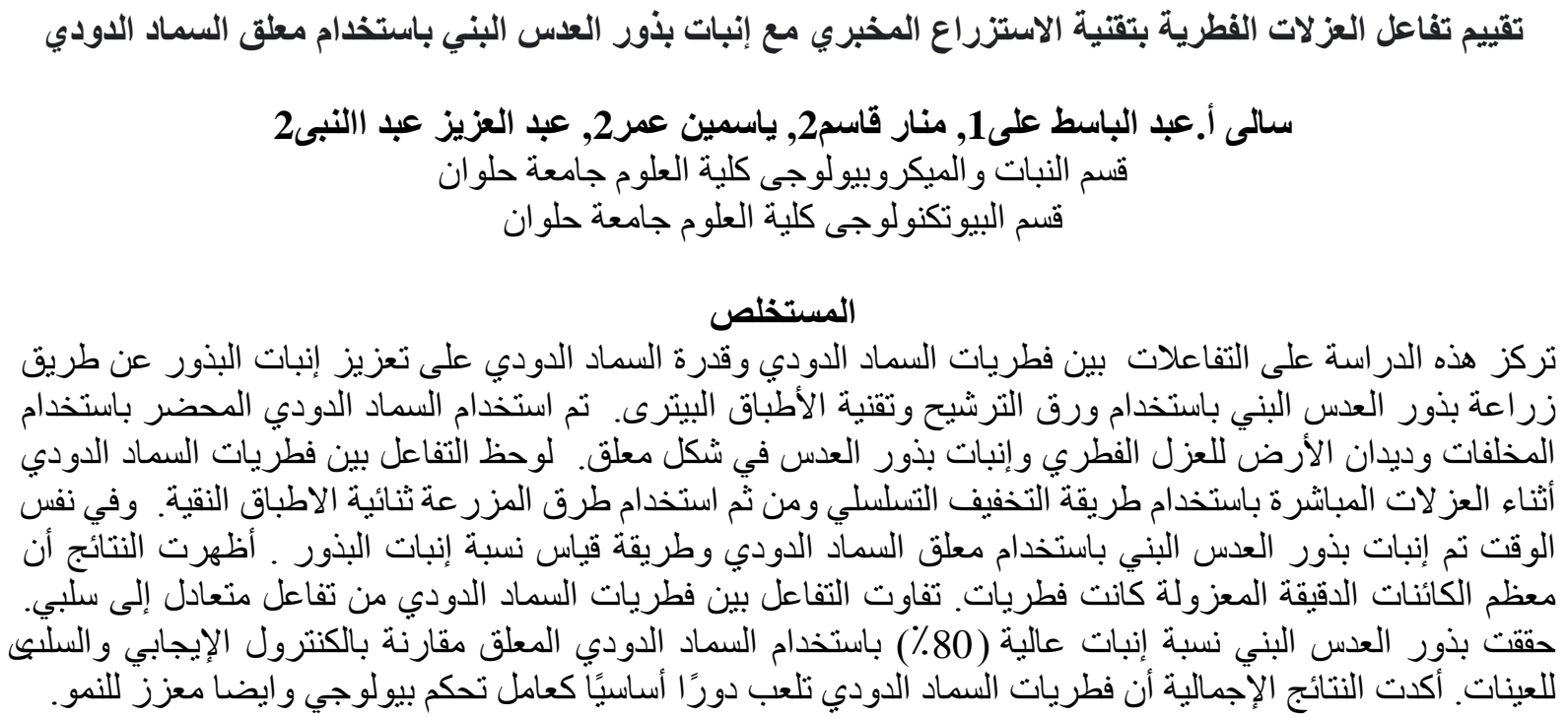

